
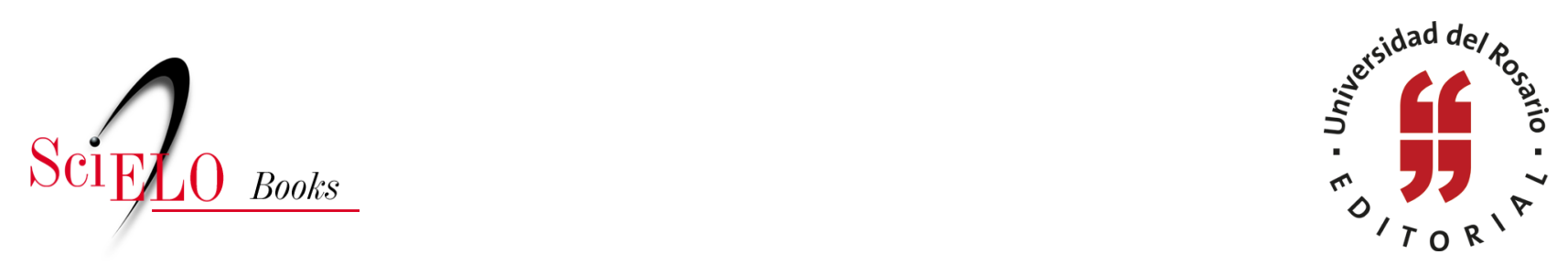

\title{
2. Enfoques teóricos de los estudios sobre clientelismo en Colombia
}

\author{
Laura Daniela Guerrero García
}

\section{SciELO Books / SciELO Livros / SciELO Libros}

GUERRERO GARCÍA, L.D. Enfoques teóricos de los estudios sobre clientelismo en Colombia. In: Clientelismo político, ¿desviación de la política o forma de representación?: Estado del arte sobre las aproximaciones al clientelismo en Colombia 1973-2011 [online]. Bogotá: Editorial Universidad del Rosario, 2014, pp. 25-46. Opera prima collection. ISBN: 978-958-738-552-6. https://doi.org/10.7476/9789587385526.0004.

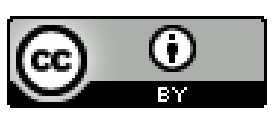

All the contents of this work, except where otherwise noted, is licensed under a Creative Commons Attribution 4.0 $\underline{\text { International license. }}$

Todo o conteúdo deste trabalho, exceto quando houver ressalva, é publicado sob a licença Creative Commons Atribição 4.0.

Todo el contenido de esta obra, excepto donde se indique lo contrario, está bajo licencia de la licencia Creative Commons Reconocimento 4.0 . 


\section{Enfoques teóricos de los estudios sobre clientelismo en Colombia}

Los cambios políticos de las últimas décadas impactaron no sólo al Estado, sino también a las concepciones de las ciencias sociales sobre lo público, la democracia, la ciudadanía, la participación, la transparencia y la corrupción, entre otros aspectos. De estos cambios, surgió una redefinición del clientelismo político, menos ingenua y más compleja. Las viejas concepciones funcionalistas, marxistas e institucionalistas se han redefinido y, en algunos casos, entrelazando eclécticamente, dando lugar a la emergencia de nuevas categorías analíticas.

Este capítulo da cuenta de los principales supuestos teóricos que guiaron los diferentes estudios sobre clientelismo. Su derrotero es reseñar las ideas de las que partieron los textos, en su momento, mas no hacer un tratado sobre las trasformaciones de cada enfoque desde sus orígenes hasta nuestros días.

Se observa que existe una concordancia entre los siguientes tres elementos: i) la preeminencia que tuvo cada enfoque a lo largo de las décadas estudiadas; ii) el contexto histórico-político; y iii) las tipologías sobre clientelismo empleadas por la literatura estudiada. ${ }^{20}$ Sobre este último punto, se identifican tres tipos de

\footnotetext{
${ }^{20} \mathrm{El}$ contexto será abordado en el cuarto capítulo y las tipologías en el tercero.
} 
clientelismo: i) el tradicional, ii) el moderno; y iii) de mercado. ${ }^{21}$ Cada tipo tiene unas características particulares que: hacen referencia a un tiempo determinado; interactúan con marcos conceptuales específicos; y con debates en boga en cada momento histórico.

\subsection{Funcionalismo}

La discusión teórica sobre clientelismo nació, en parte, de la distinción de los conceptos de comunidad y sociedad planteadas por Fernando Tönnies, Max Weber y Talcott Parsons. ${ }^{22}$ En los años sesenta, un grupo de antropólogos se interesó por el estudio de estructuras sociales definidas como arcaicas, tomando distancia de los énfasis evolutivos de la época. ${ }^{23}$ Los temas del desarrollo, la modernidad y el capitalismo fueron los problemas prioritarios para abordar la relación entre el clientelismo y las sociedades arcaicas.

El marco analítico de estos estudios fue el funcionalista, que desplazó conceptos biológicos al campo de las ciencias sociales. La sociedad fue descrita, entonces, como un organismo compuesto por partes, que tendían a adaptarse a las condiciones del ambiente: el grado de adaptación de las partes, por ende, definía la naturaleza funcional o disfuncional de los subsistemas. ${ }^{24} \mathrm{Las}$ sociedades rurales fueron, preferencialmente, la unidad analítica

${ }^{21}$ Estas categorías ad hoc han sido construidas por diferentes autores. Comparar Andrés Dávila Ladrón de Guevara y Natalia Delgado Valera, "La metamorfosis del sistema político colombiano: ¿Clientelismo de mercado o nueva forma de intermediación?”, en Degradación o cambio: Evolución del sistema politico colombiano, compilado por Francisco Gutiérrez Sanín (Bogotá: Editorial Norma, 2002), 319-356.

${ }^{22}$ Comparar Miranda Ontaneda, Clientelismo y dominio de clase, 1.

${ }^{23}$ Comparar Duarte, Educación, 2.

${ }^{24}$ Comparar David L. Sills y otros. "Variedades de análisis funcional", en Enciclopedia Internacional de las Ciencias Sociales (Madrid: Editorial Aguilar, vol. I, 1974), 305. 
y el microanálisis fue la metodología más empleada. Los principales hallazgos fueron el carácter diádico y las relaciones cara a cara del clientelismo. ${ }^{25}$

Para el enfoque funcionalista, la estructura social, por definición asimétrica, es una urdimbre de roles desempeñados por individuos. Allí, toda relación diferente a la familia nuclear se configura contractualmente. ${ }^{26}$ En este contexto, el clientelismo fue asumido como un contrato personal, de libre asociación e informal entre dos individuos, con diferente estatus pero con una contraprestación recíproca. ${ }^{27}$ Las tres relaciones que señalaba el enfoque en función de la estructura social (piramidal y jerárquica) eran: i) la relación patrón-cliente ( $\mathrm{P}-\mathrm{C})$; ii) la relación patrón-patrón $(\mathrm{P}-\mathrm{P})$; y iii) la relación cliente-patrón (C-P). ${ }^{28} \mathrm{~A}$ partir de estos tipos de relaciones se crearon modelos para determinar la cantidad, la naturaleza y la calidad de las prestaciones y contraprestaciones entre los actores. Los teóricos que nutrieron este enfoque fueron, entre otros, Fernando Tonnies, Max Weber, Talcott Parsons, Mauss, Malinovski, Richard Thurwald, Redfild y Boscof. ${ }^{29}$

Tras su auge, el enfoque funcionalista mostró sus limitaciones analíticas. Las críticas cuestionaban el énfasis en unidades micro, cuando estas tienen conexiones o dependencias con centros de poder más amplios y los vínculos simples entre individuos sin complejidad y sin contexto. La respuesta funcionalista fue la

${ }^{25} \mathrm{El}$ concepto de contrato diádico hace referencia a un tipo específico de vínculo que se establece entre dos individuos con diferente estatus.

${ }^{26}$ Comparar Miranda Ontaneda, Clientelismo, 4.

${ }^{27}$ María Clara Torres Bustamante, El fenómeno del clientelismo político: Visión de los funcionalistas y de los marxistas, consultado octubre 15, 2012, http://www.institut-gouvernance.org/es/analyse/fiche-analyse-43.html.

${ }^{28}$ Comparar Miranda Ontaneda, Clientelismo, 6.

${ }^{29}$ Comparar Fernán E. González, “Clientelismo”, 69. 
introducción de nociones tales como la de bróker, intermediario o mediador, al igual que el análisis de redes y triadas y los estudios de grupos de poder y de partidos.

En Colombia, son pocas las obras que se inscriben exclusivamente en el enfoque funcionalista. Una de ellas es la ya citada de Steffen Walter Schmidt sobre el sistema bipartidista en 1972. Este autor estableció las formas básicas de operación y los rasgos característicos de las relaciones P-c en Colombia. ${ }^{30}$

El debate académico nacional reconoce que el enfoque funcionalista fue el punto de partida para los estudios de clientelismo colombiano. No obstante, las discusiones se han centrado en señalar sus límites. Ronald Archer, por ejemplo, sostiene que en la relación patrón-cliente, la asociación del patrón con grandes propietarios y del cliente con campesinos sin tierra se prestan para interpretar que la trasformación social de los roles da por terminada la relación clientelista, lo cual es erróneo. ${ }^{31}$

No en vano, desde el enfoque funcionalista el clientelismo fue asumido como un problema que tendería a desaparecer con la llegada del desarrollo. Sin embargo, pese a las transformaciones del país y su inserción económica en el mundo capitalista, el clientelismo persiste, se reproduce, se transforma y se adapta a los cambios institucionales.

\subsection{Enfoque marxista}

El enfoque marxista abordó el clientelismo al advertir que este no era un asunto exclusivo de sociedades atávicas e indicó que eran

\footnotetext{
${ }^{30}$ Comparar Schmidt, "Political Clientelism".

${ }^{31}$ Comparar Archer, Ronald P. The Transition from Traditional to Broker Clientelism in Colombia: Political Stability and Social Unrest (Notre Dame, Indiana: Kellogg Institute for International Studie, 1990), 6-7.
} 
las relaciones de producción las que explicaban cómo y a favor de quién funcionaba el sistema. ${ }^{32}$ De ahí que le imprimiera al análisis una perspectiva histórica y de clase en situaciones socioeconómicas concretas.

Este enfoque describió al clientelismo como un modo de obrar político y una transacción bajo las reglas del dar y recibir, que puede ser traducida en "dar un poco de poder a quien le hace falta". ${ }^{33}$ En consecuencia, el clientelismo fue definido en términos de instrumentalización de una clase, dueña de los medios de producción político-económicos, sobre otra desprotegida a la que se le saca el mayor beneficio; en síntesis, un modo de explotación del hombre por el hombre. ${ }^{34}$

Miranda Ontaneda abordó, por primera vez, el problema del clientelismo en Colombia desde una perspectiva teórica marxista. Su trabajo tomó las tesis del clientelismo como una relación diádica presente en la perspectiva funcionalista. ${ }^{35}$ También, Miranda se apoyó en la obra de Guillén Martínez, ${ }^{36}$ quien realizó una génesis del clientelismo a partir de categorías que tomaron distancia de las weberianas ${ }^{37}$, para proponer un análisis de las

${ }^{32}$ Comparar González, “Clientelismo”, 69.

${ }^{33}$ Ver Miranda Ontaneda, Clientelismo, 20.

${ }^{34}$ Comparar Nicolás Jaramillo, Clientelismo y poder: relectura crítica de algunas reflexiones hechas sobre el clientelismo en Colombia (Bogotá: Universidad Nacional de Colombia, Facultad de Derecho, Ciencias Políticas y Sociales, 2005), 15.

${ }^{35}$ Los postulados teóricos elaborados por Miranda Ontaneda sirvieron de sustento teórico para la gran mayoría de obras enmarcadas en la teórica marxista. Fue a partir de este marco que se elaboraron los estudios de caso regionales publicados en 1980.

${ }^{36}$ Comparar Fernando Guillén Martínez, El poder político en Colombia, (Bogotá: Punta de lanza, 1979). La primera versión en mimeógrafo fue circulada internamente por el Centro de Investigaciones para el Desarrollo (cID) de la Universidad Nacional en 1973.

${ }^{37}$ Guillén Martínez hace una propuesta desde la historia integral y la sociología interpretativa a partir de categorías como las de tipos construidos. Su propuesta es difícil de 
formas de asociación presentes en la historia colombiana tales como: la encomienda, la hacienda y el sindicalismo. Así, señaló que tales formas de agrupación se articularon como mecanismos sutiles pero efectivos de dominación de las élites, que se trasladaron a la esfera política vía los dos partidos tradicionales y se reprodujeron a partir de lógicas clientelistas en el nivel burocrático. ${ }^{38}$

Los estudios marxistas del clientelismo, como se anotó anteriormente, aportaron una perspectiva histórica y de clase social al análisis del mismo. Desde esta postura, las relaciones de patronazgo presentes en el campo absorben las formas de producción capitalista, produciendo un biato cultural que hunde al país en un estado de producción pre-capitalista y pre-moderno. ${ }^{39} \mathrm{El}$ clientelismo es un mecanismo de dominación de las élites que permite reproducir y mantener las lealtades verticales e impedir la creación de asociaciones en su sentido horizontal. ${ }^{40}$

Sin embargo, cuando el clientelismo manifestó ser un fenómeno que también podía darse entre clases y en todas direcciones, los postulados marxistas perdieron alcance y capacidad explicativa. Además, su referencia a grandes estructuras, partidos, clases, el Estado, cuya figura central era casi exclusivamente el terrateniente

clasificar en un enfoque, sin embargo es claro que sus postulados son insumo fundamental para las vertientes institucionalista, marxista y estructural-funcionalista. En esta oportunidad se clasificó a Guillén dentro del enfoque estructuralista debido a que su tesis se fundamenta en la existencia de estructuras de larga duración adscriptivas desde la encomienda y la hacienda, las cuales instauraron formas de poder establecidas desde el periodo colonial hasta el momento de la escritura del texto.

${ }^{38}$ Néstor Miranda Ontaneda, "El poder político en Colombia", Enfoques colombianos, (1980): 39 .

${ }^{39}$ Comparar Jorge Valenzuela Ramírez, Producción, 35.

${ }^{40}$ Comparar Miranda Ontaneda, "El poder", 46. 
o el gamonal o cacique, impedían su efectividad y aplicabilidad. ${ }^{41}$ De otra parte, la idea de un "pre-capitalismo" agrario anacrónico le restó vigencia y capacidad explicativa sobre la naturaleza del campesinado y sus articulaciones con el capitalismo urbano. Actualmente, este enfoque se ha trasformado y su campo de análisis ha migrado a otros asuntos tales como el sindicalismo, los movimientos sociales, los análisis de grupo y de género, entre otros.

\subsection{Enfoque estructural-funcionalista}

Este enfoque comparte con el funcionalista la herencia de conceptos de las ciencias naturales con modificaciones sustanciales al trascender la biología y ver la sociedad como un gran sistema articulado por subsistemas. Con ello va más allá de la explicación del funcionamiento interno de la unidad para entender cómo se relaciona esta con un entorno mucho más amplio. Desde esta perspectiva, los conceptos de estructura social, de sistema, de función, rol, estatus y de proceso adquieren un papel central: "La estructura social es la trama de posiciones e interrelaciones mutuas mediante las cuales se puede explicar la interdependencia de las partes que conforman la sociedad. La función de cada parte es la forma en que esa parte opera para mantener el sistema total en buena salud". ${ }^{42}$

En Colombia, Leal y Dávila adoptan este enfoque para superar las dificultades analísticas de los trabajos precedentes sobre clientelismo. Su investigación articuló el macro-análisis con el micro-análisis, explicando el funcionamiento del sistema político colombiano a partir de la comprensión de su unidad más pequeña: el municipio y de su articulación con el sistema en su conjunto. En este contexto, el clientelismo se describe como aquello que

\footnotetext{
${ }^{41}$ Martz, The Politics, 14.

${ }^{42}$ Ver Sills y otros, Enciclopedia, vol. I, 299.
} 
“[...] comanda al conjunto de relaciones sociales que definen la forma real como opera la política (sistema), a partir de las normas establecidas para el efecto por el Estado (régimen). El Estado, a su vez, expresa la organización de las relaciones de poder en la sociedad, materializadas en un conjunto de instituciones administradas por los gobiernos". ${ }^{43}$

Los autores plantearon que el clientelismo se convirtió en una relación fundamental para el sistema político tras el Frente Nacional. En este período, los partidos tradicionales se apoyaron en el clientelismo para contener la crisis política que el país vivía. Es de anotar que Leal y Dávila se nutren del trabajo de Fernando Guillén Martínez, quien definió la estructura social

Como el conjunto sistemático de normas, expectativas y actitudes que condicionan las relaciones humanas -por esto- es fácil ver que ellas se originan como instituciones formales o informales, en el seno de las asociaciones predominantes. Estas asociaciones, resultado de innumerables factores, entre los cuales tienen capital importancia las relaciones de producción y la composición histórica y demográfica, proyectan su sistema de "status roles" sobre el conjunto de la sociedad en la cual se insertan y la tiñen de su propia tonalidad específica. Al final, la estructura social, en su conjunto (simbología, sistema de roles, status, y valores) no es otra cosa que una ampliación de la estructura de las asociaciones dominantes. ${ }^{44}$

\footnotetext{
${ }^{43}$ Ver Leal Buitrago y Dávila Ladrón de Guevara, Clientelismo, 48.

${ }^{44}$ Ver Guillén Martínez, El poder politico en Colombia, xi y ss.
} 
El alcance del poder político está condicionado por el lugar que los actores ocupan en dicha estructura de poder. Los partidos políticos, de esta forma, se consolidan como una red de relaciones de dependencia jerárquica, cuyo objetivo es la cooptación de presupuesto público para el mantenimiento de una exclusiva clientela patronal. ${ }^{45}$ En este orden, el clientelismo adquiere un papel fundamental en el mantenimiento del orden sociopolítico del sistema. ${ }^{46}$

Los autores que se inscriben en el estructural-funcionalismo prefieren el término de sistema político y no el de régimen. $\mathrm{Al}$ respecto, Javier Torres señala que "[...] la respuesta es que los sistemas políticos dan cuenta del verdadero funcionamiento de lo político en una sociedad, es decir, de las reglas informales que hacen parte del ejercicio político. Mientras que el concepto de régimen político se limita a la normatividad, a las reglas formales que arbitran el funcionamiento de la política". ${ }^{47}$

Es decir, el régimen es resultado de unas dinámicas que los sujetos, inmersos en una estructura social de roles, le imprimen, dándole un carácter propio que solo puede ser observado a partir del funcionamiento del sistema en general. La principal limitación de este enfoque es que tiende más que a explicar, a justificar las relaciones de la sociedad. No en vano, son los autores que se emparentan con este enfoque los que iniciaron la tendencia de atribuir funciones positivas al clientelismo.

${ }^{45}$ Comparar Jaramillo, Clientelismo y poder: relectura, 12.

${ }^{46}$ Comparar Martz, The Politics, 8.

${ }^{47}$ Ver Javier Fernando Torres Preciado, "Vicio y virtud : el sistema político colombiano en el periodo 1848-1885” (tesis de maestría, Universidad de los Andes, Bogotá, 2008), 12. 


\subsection{Enfoque neo-institucionalista}

Los preceptos del nuevo institucionalismo emergieron durante las décadas de los setenta y ochenta en contraposición a los enfoques conductista, de elección racional y funcionalista. Sin embargo, y muy paradójicamente, el enfoque representa una reformulación teórica que mantiene algunos postulados del viejo institucionalismo, del conductismo, de la elección racional y de la psicología cognitiva. ${ }^{48}$ Por lo anterior, se ha generado un amplio debate entre los autores y diferentes versiones del neoinstitucionalismo, lo que ha generado dificultad en la identificación de las tendencias teóricas de los estudios sobre clientelismo que han sido producidos en Colombia. Dentro de esta clasificación, fueron incluidos todos los estudios que dieron prioridad a las instituciones, siendo estas formales o informales, o que hicieron uso de enfoques enmarcados dentro de la elección racional.

A diferencia del funcionalismo y del conductismo, el nuevo institucionalismo concibe la historia como un proceso complicado que no necesariamente conduce a formas más elevadas de organización política. ${ }^{49}$ Es decir, la nueva perspectiva rompe con la idea de progreso lineal. En segundo lugar, a diferencia de la elección racional, establece que los actores políticos reflejan los valores de las instituciones a las que están vinculados y, por tanto, su accionar no responde solamente a la maximización del beneficio

${ }^{48}$ Comparar Rodrigo Losada Lora y Andrés Casas Casas, Enfoques para el análisis politico: historia, epistemología y perspectivas de la ciencia política (Bogotá: Editorial Pontificia Universidad Javeriana, 2010), 178.

${ }^{49}$ Ibid., 179. 
personal; ${ }^{50}$ así como también se rompe con los reduccionismos de atribuir accionares colectivos a comportamientos individuales. ${ }^{51}$

El viejo institucionalismo del siglo xix consideraba a las instituciones sociales como "los núcleos básicos de la organización social, comunes a todas las sociedades y encargadas de algunos de los problemas fundamentales de toda vida social ordenada". ${ }^{52}$ La nueva perspectiva teórica, en un esfuerzo por estudiar las dinámicas al interior de las instituciones, tanto formales como informales, y los intereses en juegos, tanto de individuos como de grupos, no solo parte del rol fundamental de las instituciones, sino que agrega tres elementos más: en primer lugar, integra conceptos y preceptos económicos a las viejas perspectivas centradas en las instituciones; como producto de lo anterior, trasciende las teorías tradicionales concediéndole un rol importante tanto a las instituciones como a los actores sociales e individuales y a su comportamiento racional; $y$ finalmente, supone que el orden es el resultado del cumplimiento de las normas anteriormente establecidas, por lo que un cambio solo puede ser dado de forma paulatina e incremental. ${ }^{53}$

Los estudios sobre clientelismo en Colombia han estado muy influenciados por algunos preceptos del viejo institucionalismo pero, sobre todo, se nutren de presupuestos que reformularon la perspectiva sobre las instituciones sociales.

En la década del ochenta, desde el neoinstitucionalismo se empezó a estudiar el clientelismo político en Colombia. Rodrigo

\footnotetext{
${ }^{50}$ Comparar Federico Rivera Romero, "El neoinstitucionalismo y la investigación en las ciencias sociales”, Revista Centroamericana de Administración Pública-ICAP, (2013): 101-128.

${ }^{51}$ Comparar Losada Lora y Casas Casas, Enfoques, 178.

${ }^{52}$ Ver Sills y otros, Enciclopedia, vol. I, 299.

${ }^{53}$ Comparar Rivera Romero, "El neoinstitucionalismo”, 102.
} 
Losada investigó el comportamiento electoral desde el paradigma de la elección racional. ${ }^{54}$ Años más tarde, se identificaron trabajos que abordaron el clientelismo desde la perspectiva del interés individual, a partir de teorías de juegos. ${ }^{55}$ En la década del noventa se vivió el auge de los estudios centrados en las instituciones. Desde un mismo paradigma, se generaron aproximaciones que parten del mismo principio, pero dan soluciones diametralmente opuestas al fenómeno. Por un lado, están los estudios que definen al clientelismo como la principal institución informal que distorsiona el funcionamiento de las instituciones formales tales como la democracia y el Estado social de derecho. El trabajo de Mauricio García y Javier Revelo se inscribe en esta corriente afirmando que:

Existe una relación inversa entre clientelismo y la ley: a mayor importancia de aquel en la determinación de los comportamientos ciudadanos y de los funcionarios públicos, menor el peso de esta y viceversa. Por eso el clientelismo está en contravía del Estado de Derecho, y por eso mismo la mayor importancia de las relaciones clientelistas entraña un aumento de la debilidad institucional. ${ }^{56}$

${ }^{54}$ Comparar Losada Lora, Clientelismo.

${ }^{55}$ Comparar Jorge Andrés Gallego Durán y Rafael Raciborsky, Clientelism, Income, Inequality, and Social Preferences: An Evolutionary Approach to Poverty Traps, consultado agosto 29,2014, http://growth-institutions.ec.unipi.it/pages/InstitutionI/clientelism.pdf)); Rafael José Santos Villagrán, “Bogotá:The Collapse of a Political Machine”(cuadernillo no publicado Universidad de los Andes, Facultad de Economía, Bogotá, 2007).

${ }^{56}$ Ver Mauricio García Villegas y Javier Eduardo Revelo Rebolledo. Estado alterado. Clientelismo, mafias y debilidad institucional en Colombia (Bogotá: Centro de estudios de Derecho, Justicia y Sociedad), 23. 
Por otro lado, están los estudios que indican que la institución informal del clientelismo se ha trasformado a partir de cambios en el régimen legal. Desde esta perspectiva, el clientelismo es una institución que carece de los formalismos y de la fuerza legal de las relaciones contractuales, siendo una relación semi-ilegal que, aunque no viola las leyes, sí va en contra de los principios éticos. ${ }^{57}$ Se trata de un pacto social que está determinado por valores tales como la lealtad. Es, sin duda, una institución que se entrelaza con las instituciones formales, dando como resultado procesos diferentes a los establecidos dentro de las normas formales. Estudios representativos de este enfoque son, por ejemplo, el de Francisco Gutiérrez y Andrés Dávila. Sus trabajos sostienen que a partir de 1991, la estructura piramidal del clientelismo moderno se trasformó en uno de mercado, que da cabida a dinámicas de participación y representación política, visión que imprime una postura más comprensiva del fenómeno. ${ }^{58}$

Introduce así el neoinstitucionalismo visiones contradictorias del clientelismo, negativas o pragmáticamente positivas. Cuando los estudios enmarcados en esta corriente descargan toda responsabilidad en instituciones como el Estado y el gobierno, se dice que se exime de su papel proactivo a actores individuales y colectivos de la sociedad civil. Adicionalmente, los estudios con modelos económicos del fenómeno terminan por generar reduccionismos del fenómeno.

${ }^{57}$ Comparar Duarte, Educación, 8.

${ }^{58}$ Comparar Dávila Ladrón de Guevara y Delgado Varela, La metamorfosis Francisco Gutiérrez Sanín, “Clientelismo y sus enredos”. 


\subsection{Enfoque socio-antropológico}

Para José González hasta la década del noventa los estudios sobre clientelismo se inscribían en dos grandes lineamientos teóricos: i) la teoría liberal, más cercana a la derecha política, y ii) la marxista, proclive a la izquierda. González observa que en el marco de una sociedad con aspiraciones igualitarias, principios universalistas y sistemas democráticos de avanzada, la humanidad se enfrenta con el problema de la persistencia del homo bierarchicus sobre el homo aequalis. En este contexto, desde la derecha, el clientelismo es asumido como un fenómeno "natural", dado su visión jerarquizada y patriarcal del mundo. No cuestionar esta postura condena a la humanidad a una vida de clientelismo y le resta su carácter dinámico y socio-histórico. La izquierda, por su parte, combate al clientelismo a toda costa para lograr la igualdad plena. No obstante, sus regímenes políticos no han logrado tal igualdad, ni han superado prácticas clientelistas. ${ }^{59}$

Para González, ninguna de estas aproximaciones permitió repensar conceptualmente al clientelismo, ni replantear sus prácticas. Por tanto, propone observarlo como un fenómeno propio del mundo actual, que se evidencia por el choque entre patrones culturales y tipos ideales. No es, entonces, producto de relaciones feudales o arcaicas, sino más bien de una tensión, que sólo es posible resolver a partir de la superación de las visiones moralistas. Además, anota que el clientelismo social y político constituye un universo antropológico. ${ }^{60}$

Los planteamientos de González Alcantud sintetizan el enfoque socio-antropológico. En términos generales, Rodrigo Losada

${ }^{59}$ Comparar José A. González Alcantud, El clientelismo politico. Perspectiva socioantropológica (Barcelona: Anthropos Editorial, 1997).

${ }^{60}$ Ibid., 21. 
y Andrés Casas, quienes lo denominan enfoque histórico-sociológico, lo refieren como una visión que da prioridad al estudio del entorno social y cultural. Así mismo, los datos son construidos a partir de fenómenos observables empíricamente, en donde se parte de la posibilidad de identificar tendencias constantes en la política y devenir de los pueblos y sociedades; por lo mismo, la historia se convierte en el principal instrumento para comprensión de los fenómenos. Tal como se muestra, su interés recae más que en individuos, en grandes colectividades humanas como la sociedad, los pueblos, las culturas, el Estado, etc. ${ }^{61}$

Aterrizando los preceptos del enfoque socio-antropológico al campo del clientelismo político, se identifica que los planteamientos de González Alcantud se configuraron como el primer referente de los estudios de este corte durante el presente siglo en Colombia. Estos se caracterizaron por tomar distancia de la visión moralista y por adoptar dimensiones ancladas a la cultura política, donde se hizo referencia a dinámicas sociales como la creación de ciudadanía, la participación y la representación política, todas dinámicas observables al anterior del mismo fenómeno clientelista. Así mismo, el clientelismo es tomado como algo más allá de un simple fenómeno atávico. ${ }^{62}$ En este contexto, es de citar el trabajo de Rocío Rubio, quien estudió la red clientelista del político

${ }^{61}$ Comparar Losada Lora y Casas Casas, Enfoques, 148.

${ }^{62}$ Dentro de las obras que abordan la problemática desde esta perspectiva son de relatar: Miguel García Sánchez, ¿Ciudadanía avergonzada? Democracia local y construcción de ciudadanía en Bogotá (Bogotá: Universidad de los Andes y Universidad Nacional de Colombia, 2003); Miguel García Sánchez, "La política bogotana, un espacio de recomposición (1982-2001)", en Degradación o cambio: evolución del sistema politico colombiano, compilado por Francisco Gutiérrez Sanín (Bogotá: Editorial Norma, 2002); Escalante, "Clientelismo", 31-41. 
conservador Telésforo Pedraza y la definió como una forma de hacer política. La autora anota que su tesis sobre el clientelismo

[...] marca una distancia frente a aquellos que lo narran como un fenómeno atávico, pre moderno o como un rezago de las formas arcaicas del quehacer político, así como frente a aquellos que lo observan como un mecanismo articulador entre las formas pre modernas de lo político ylas modernas. Tal distancia no implica observar el clientelismo como un fenómeno absolutamente moderno que subordina elementos pre-modernos. Se esgrime la hipótesis según la cual este fenómeno se apoya en tales elementos. Son estos finos hilos a través de los cuales se teje la trama de las redes clientelares y, en el caso del teleforismo, relatan una racionalidad particular y la aplicación de un principio de economía para su producción eficiente. Se trata, entonces, de interrogar hasta dónde se han modificado los mecanismos de producción y reproducción de la red teleforista, a quien sirven y en qué contextos [...] también se toma distancia de las tesis que observan el carácter universal del clientelismo. Por otra parte, se tienden puentes a las miradas políticas del fenómeno en el país. Algunas han justificado de cierto modo su existencia, expresando que es un fenómeno universal asociado a condiciones de desigualdad socioeconómica, mientras que otras lo han señalado como la mayor patología del sistema político. $\mathrm{El}$ texto invita a superar las anteriores versiones. En el primer caso, porque no permite anotar particularidades del fenómeno, y pareciera que mientras no se superen las desigualdades, el clientelismo será consustancial al 
quehacer político. En el segundo, porque tras las tensiones de políticos "clientelistas" versus "no clientelistas", "presentables" versus "representables", "independientes" versus "tradicionales", "sanos" versus "corruptos", se esconden densas relaciones entre unos y otros, y se negocian apoyos; y, por último, porque ninguna de las dos categorías puede ser tomada a priori como condición de moralidad pública. $^{63}$

En síntesis, la transformación de los paradigmas ha conducido a replantear las formas de aproximación al clientelismo: se presentó un desplazamiento de las ideas sobre desarrollo y capitalismo hacia un análisis de clase y el estudio de las instituciones formales. Actualmente, el clientelismo es asumido como un universo complejo, que puede sufrir trasformaciones a partir de las reformas al régimen. Las nuevas aproximaciones se caracterizan por posturas más comprensivas del fenómeno, donde la dimensión de la cultura y el comportamiento político adquieren un papel fundamental en los análisis. A manera de conclusión de este acápite, se presentan a continuación cinco tablas que sintetizan los principales rasgos de cada uno de los enfoques identificados en este trabajo.

${ }^{63}$ Ver Rubio Serrano, No hay paraísos, 15-16. 
Tabla 1. Rasgos del enfoque funcionalista en el clientelismo político

\begin{tabular}{|c|c|c|c|}
\hline \multirow[b]{2}{*}{$\begin{array}{l}\text { Enfoque o } \\
\text { paradigma }\end{array}$} & \multicolumn{2}{|c|}{ Características } & \multirow[b]{2}{*}{ Críticas al enfoque } \\
\hline & Generales & $\begin{array}{c}\text { Aplicadas al estudio } \\
\text { del clientelismo }\end{array}$ & \\
\hline Funcionalista & $\begin{array}{l}\text { La sociedad fue } \\
\text { entendida como } \\
\text { un organismo } \\
\text { compuesto por } \\
\text { partes que tendían } \\
\text { a adaptarse a las } \\
\text { condiciones del } \\
\text { ambiente. } \\
\text { La adaptación de } \\
\text { los subsistemas a } \\
\text { las condiciones del } \\
\text { ambiente definía } \\
\text { la funcionalidad o } \\
\text { disfuncionalidad } \\
\text { de los mismos. }\end{array}$ & $\begin{array}{l}\text { Las sociedades } \\
\text { rurales o sociedades } \\
\text { consideradas } \\
\text { "arcaicas" fueron } \\
\text { preferentemente } \\
\text { tomadas como las } \\
\text { unidades de análisis } \\
\text { y el microanálisis fue } \\
\text { la metodología más } \\
\text { empleada. } \\
\text { La relación clientelar } \\
\text { es asumida como un } \\
\text { contrato personal, } \\
\text { de libre asociación } \\
\text { e informal entre } \\
\text { dos individuos, con } \\
\text { diferente estatus } \\
\text { pero con una } \\
\text { contraprestación } \\
\text { recíproca. } \\
\text { Estos primeros } \\
\text { estudios establecieron } \\
\text { las características } \\
\text { base del clientelismo: } \\
\text { el carácter diádico y } \\
\text { la relación cara a cara. } \\
\text { Establece relaciones } \\
\text { en tres direcciones: i) } \\
\text { la relación patrón- } \\
\text { cliente (p-c); ii) la } \\
\text { relación patrón- } \\
\text { patrón (p-P);iii) } \\
\text { la relación cliente- } \\
\text { patrón (c-P). }\end{array}$ & $\begin{array}{l}\text { El clientelismo fue } \\
\text { asociado con una forma } \\
\text { de subdesarrollo. El } \\
\text { fenómeno estaba dado } \\
\text { a desaparecer con la } \\
\text { llegada de la modernidad. } \\
\text { Se introdujo el concepto } \\
\text { de bróker o intermediario } \\
\text { y el estudio de redes y } \\
\text { triadas. }\end{array}$ \\
\hline
\end{tabular}

Fuente: Tabla elaborada por el autor con base en la información presente en las fichas bibliográficas elaboradas. 
Tabla 2. Rasgos del enfoque marxista en el clientelismo político

\begin{tabular}{|c|c|c|c|}
\hline \multirow{2}{*}{$\begin{array}{l}\text { Enfoque o } \\
\text { paradigma }\end{array}$} & \multicolumn{2}{|c|}{ Características } & \multirow[b]{2}{*}{ Críticas al enfoque } \\
\hline & Generales & $\begin{array}{l}\text { Aplicadas al estudio del } \\
\text { clientelismo }\end{array}$ & \\
\hline \multirow{3}{*}{ Marxista } & $\begin{array}{l}\text { Las relaciones } \\
\text { de producción } \\
\text { constituyen la base } \\
\text { de la estructura } \\
\text { económica y por ende } \\
\text { la base de la sociedad. } \\
\text { (Losada, Rodrigo, } \\
\text { 2010, p. 263) }\end{array}$ & $\begin{array}{l}\text { Imprime a los estudios } \\
\text { de clientelismo el análisis } \\
\text { histórico y de clase. }\end{array}$ & $\begin{array}{l}\text { El clientelismo } \\
\text { manifestó ser un } \\
\text { fenómeno que podía } \\
\text { darse entre clases, } \\
\text { pero también en } \\
\text { todas direcciones, } \\
\text { restando alcance } \\
\text { y capacidad } \\
\text { explicativa al } \\
\text { enfoque marxista. }\end{array}$ \\
\hline & $\begin{array}{l}\text { Las condiciones } \\
\text { materiales están } \\
\text { determinadas } \\
\text { por los modos } \\
\text { de producción, } \\
\text { la propiedad y la } \\
\text { tenencia de la tierra. }\end{array}$ & $\begin{array}{l}\text { El clientelismo fue } \\
\text { definido en términos de } \\
\text { instrumentalización de } \\
\text { una clase, dueña de los } \\
\text { medios de producción } \\
\text { político-económicos, } \\
\text { sobre otra desprotegida a } \\
\text { la que se le saca el mayor } \\
\text { beneficio. }\end{array}$ & $\begin{array}{l}\text { La referencia a las } \\
\text { grandes estructuras } \\
\text { de poder, partidos, } \\
\text { élites o clases generó } \\
\text { dificultades para } \\
\text { operacionalizar } \\
\text { y estudiar el } \\
\text { fenómeno. }\end{array}$ \\
\hline & $\begin{array}{l}\text { Existe una relación } \\
\text { de dominación de } \\
\text { unas clases sobre } \\
\text { otras. }\end{array}$ & $\begin{array}{l}\text { Introdujo el } \\
\text { macroanálisis: la relación } \\
\text { de dominación entre } \\
\text { sociedades pequeñas y los } \\
\text { centros de poder. }\end{array}$ & $\begin{array}{l}\text { La referencia al } \\
\text { sector rural como } \\
\text { premoderno y } \\
\text { precapitalista restó } \\
\text { vigencia y capacidad } \\
\text { explicativa a las } \\
\text { relaciones actuales } \\
\text { del campesinado y al } \\
\text { agro colombiano. }\end{array}$ \\
\hline
\end{tabular}

Fuente: Tabla elaborada por el autor del presente trabajo con base en la información presente en las fichas bibliográficas elaboradas. 
Tabla 3. Rasgos del enfoque estructural-funcionalista en el clientelismo político

\begin{tabular}{|c|c|c|c|}
\hline \multirow[b]{2}{*}{$\begin{array}{l}\text { Enfoque o } \\
\text { Paradigma }\end{array}$} & \multicolumn{2}{|c|}{ Características } & \multirow[b]{2}{*}{ Críticas al enfoque } \\
\hline & Generales & $\begin{array}{l}\text { Aplicadas al } \\
\text { estudio del } \\
\text { clientelismo }\end{array}$ & \\
\hline $\begin{array}{l}\text { Estructural- } \\
\text { funcionalista }\end{array}$ & $\begin{array}{l}\text { Integra preceptos } \\
\text { básicos de los } \\
\text { enfoques: funcionalista, } \\
\text { estructuralista y } \\
\text { sistémico. } \\
\text { Entiende la estructura } \\
\text { social como el conjunto } \\
\text { sistemático de normas, } \\
\text { expectativas y actitudes } \\
\text { que condicionan } \\
\text { las relaciones } \\
\text { humanas, originando } \\
\text { instituciones formales } \\
\text { o informales en el seno } \\
\text { de las asociaciones } \\
\text { predominantes. } \\
\text { Explica el } \\
\text { funcionamiento interno } \\
\text { de la unidad en su } \\
\text { relación con su entorno } \\
\text { inmediato. } \\
\text { Aplica conceptos de la } \\
\text { biología a las ciencias } \\
\text { sociales. Los conceptos } \\
\text { fundamentales son los de } \\
\text { estructura social, sistema, } \\
\text { función, rol, estatus y } \\
\text { proceso. }\end{array}$ & $\begin{array}{l}\text { El clientelismo } \\
\text { adquiere un papel } \\
\text { fundamental en el } \\
\text { mantenimiento del } \\
\text { orden sociopolítico } \\
\text { del sistema. } \\
\text { Acude a la } \\
\text { diferenciación de } \\
\text { los conceptos de } \\
\text { régimen político } \\
\text { y del sistema } \\
\text { político, matizando } \\
\text { las dinámicas de } \\
\text { las instituciones } \\
\text { informales y de las } \\
\text { formales. } \\
\text { Articula el } \\
\text { microanálisis con el } \\
\text { macroanálisis. }\end{array}$ & $\begin{array}{l}\text { La principal } \\
\text { limitación de este } \\
\text { enfoque es que } \\
\text { tiende, más que a } \\
\text { explicar, a justificar } \\
\text { las relaciones de la } \\
\text { sociedad. }\end{array}$ \\
\hline
\end{tabular}

Fuente: tabla elaborada por el autor del prsente trabajo con base en lainformación presente en las fichas bibliográficas elaboradas. 
Tabla 4. Rasgos del enfoque institucionalista en el clientelismo político

\begin{tabular}{|c|c|c|c|}
\hline \multirow{2}{*}{$\begin{array}{l}\text { Enfoque o } \\
\text { paradigma }\end{array}$} & \multicolumn{2}{|c|}{ Características } & \multirow[b]{2}{*}{ Críticas al enfoque } \\
\hline & Generales & $\begin{array}{l}\text { Aplicadas al estudio del } \\
\text { clientelismo }\end{array}$ & \\
\hline \multirow{6}{*}{ 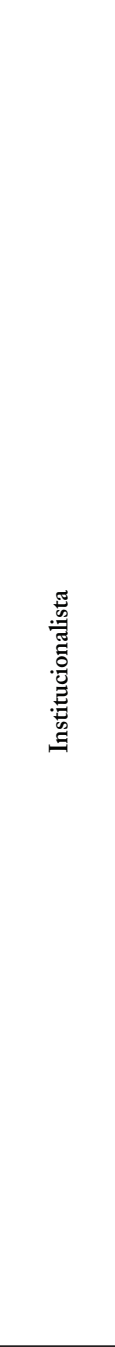 } & $\begin{array}{l}\text { Analiza las } \\
\text { instituciones, los actores } \\
\text { y su comportamiento } \\
\text { racional. }\end{array}$ & $\begin{array}{l}\text { Analiza el clientelismo en } \\
\text { relación con instituciones } \\
\text { formales como: el Estado, } \\
\text { la democracia, el sistema } \\
\text { político. }\end{array}$ & $\begin{array}{l}\text { Cuando se descarga } \\
\text { toda responsabilidad en } \\
\text { instituciones como el } \\
\text { Estado y el gobierno, se } \\
\text { dice que se exime de su } \\
\text { papel proactivo a actores } \\
\text { individuales y colectivos } \\
\text { de la sociedad civil. }\end{array}$ \\
\hline & $\begin{array}{l}\text { Da un papel } \\
\text { protagónico e } \\
\text { independiente a } \\
\text { las instituciones } \\
\text { sin desconocer la } \\
\text { importancia de los } \\
\text { actores individuales, } \\
\text { incluyendo en estos los } \\
\text { procesos sociopolíticos y } \\
\text { participativos. }\end{array}$ & $\begin{array}{l}\text { Algunos autores inscritos } \\
\text { en esta perspectiva teórica } \\
\text { definen el clientelismo como } \\
\text { una relación semi-ilegal que, } \\
\text { aunque no viola las leyes, sí } \\
\text { va en contra de los principios } \\
\text { éticos; }\end{array}$ & $\begin{array}{l}\text { Algunos enfoques } \\
\text { económicos aplicados } \\
\text { al comportamiento } \\
\text { electoral se presentan } \\
\text { como visiones simplistas } \\
\text { y reduccionistas del } \\
\text { fenómeno. }\end{array}$ \\
\hline & $\begin{array}{l}\text { Integra conceptos y } \\
\text { preceptos económicos } \\
\text { a las viejas perspectivas } \\
\text { teóricas centradas en las } \\
\text { instituciones. }\end{array}$ & $\begin{array}{l}\text { como un pacto social que } \\
\text { está determinado por valores } \\
\text { tales como la lealtad; }\end{array}$ & $\begin{array}{l}\text { Algunos trabajos } \\
\text { enmarcados en el enfoque } \\
\text { de elección racional } \\
\text { han presentado fallas } \\
\text { metodológicas. }\end{array}$ \\
\hline & $\begin{array}{l}\text { El orden es el resultado } \\
\text { del cumplimiento de las } \\
\text { normas anteriormente } \\
\text { establecidas, por lo que } \\
\text { un cambio solo puede } \\
\text { ser dado de forma } \\
\text { paulatina e incremental. }\end{array}$ & $\begin{array}{l}\text { como una institución } \\
\text { informal que influye a las } \\
\text { instituciones formales. } \\
\text { Esta influencia puede ser } \\
\text { asumida como un aspecto } \\
\text { problemático o desde una } \\
\text { perspectiva comprensiva. }\end{array}$ & $\begin{array}{l}\text { Las reformas legales e } \\
\text { institucionales antes que } \\
\text { producir una erradicación } \\
\text { de un fenómeno visto } \\
\text { como algo netamente } \\
\text { negativo, ha producido la } \\
\text { mutación, complejización y } \\
\text { transformación del mismo. }\end{array}$ \\
\hline & $\begin{array}{l}\text { Rompe con la idea de } \\
\text { progreso lineal. }\end{array}$ & $\begin{array}{l}\text { Algunos estudios han } \\
\text { aplicado modelos } \\
\text { económicos para la } \\
\text { comprensión del fenómeno } \\
\text { del clientelismo a lo largo del } \\
\text { proceso electoral. }\end{array}$ & \\
\hline & $\begin{array}{l}\text { Da mayor importancia a } \\
\text { los procesos sociales que } \\
\text { a los resultados de los } \\
\text { mismos. }\end{array}$ & $\begin{array}{l}\text { Estudian el fenómeno } \\
\text { para poder producir } \\
\text { modificaciones en el mismo, } \\
\text { bien sea a partir de ingeniería } \\
\text { institucional o a partir de } \\
\text { otras medidas. }\end{array}$ & \\
\hline
\end{tabular}

Fuente: Tabla elaborada por el autor del presente trabajo con base en la información presente en las fichas bibliográficas elaboradas. 
Tabla 5. Rasgos del enfoque socio-antropológico en el clientelismo político

\begin{tabular}{|c|c|c|c|}
\hline \multirow[b]{2}{*}{$\begin{array}{l}\text { Enfoque o } \\
\text { paradigma }\end{array}$} & \multicolumn{2}{|c|}{ Características } & \multirow[b]{2}{*}{ Críticas al enfoque } \\
\hline & Generales & $\begin{array}{c}\text { Aplicadas al estudio } \\
\text { del clientelismo }\end{array}$ & \\
\hline $\begin{array}{l}\text { Socio- } \\
\text { antropológico }\end{array}$ & $\begin{array}{l}\text { Enfoque centrado } \\
\text { en el entorno social y } \\
\text { cultural. } \\
\text { Su argumentación } \\
\text { está basada en } \\
\text { hechos observables. } \\
\text { Busca identificar } \\
\text { tendencias } \\
\text { constantes en la } \\
\text { política de los } \\
\text { pueblos. } \\
\text { La historia de los } \\
\text { pueblos da una } \\
\text { comprensión de los } \\
\text { fenómenos. }\end{array}$ & $\begin{array}{l}\text { El clientelismo } \\
\text { social y político } \\
\text { constituye un universo } \\
\text { antropológico. } \\
\text { Se evidencia por el } \\
\text { choque entre patrones } \\
\text { culturales y tipos } \\
\text { ideales. } \\
\text { El clientelismo como } \\
\text { un fenómeno propio } \\
\text { de la modernidad, no } \\
\text { como un fenómeno } \\
\text { atávico. } \\
\text { Se distancia de una } \\
\text { visión moralista y } \\
\text { contempla la presencia } \\
\text { de dimensiones } \\
\text { tales como la cultura } \\
\text { política, la creación } \\
\text { de ciudadanía, la } \\
\text { participación y la } \\
\text { representación política } \\
\text { en este fenómeno. }\end{array}$ & $\begin{array}{l}\text { Es exitoso cuando } \\
\text { se trata de describir } \\
\text { procesos, pero fracasa } \\
\text { a la hora de explicar } \\
\text { los mismos. } \\
\text { La comprensión del } \\
\text { fenómeno puede } \\
\text { recurrir en una } \\
\text { justificación del } \\
\text { mismo. }\end{array}$ \\
\hline
\end{tabular}

Fuente: Tabla elaborada por el autor del presente trabajo con base en la información presente en las fichas bibliográficas elaboradas. 